Bangladesh Journal of Anatomy July 2009, Vol. 7 No. 2 pp. 105-108

\title{
Intimal Thickness of the Right Renal Artery: A Postmortem Study
}

\author{
Saifun Naher ${ }^{1}$, Humaira Naushaba², Shamim Ara ${ }^{3}$, Shahara Khatun ${ }^{4}$, Jesmin Ara Begum ${ }^{5}$
}

\begin{abstract}
:
Context: Atherosclerosis is the most frequent intimal disease of large and medium sized arteries. It is characterized by the intimal thickening and lipid deposition. Atherosclerosis can affect the kidneys directly by renal stenosis or as a frequent site of atherosclerotic disease. The seemingly increased incidence of atherosclerotic disorders in the country, their fatal consequences and the paucity of relevant data of the present study was carried out to find out such information which help workers at all levels playing their roles in planning and execution of the prevention and management aspects of atherosclerotic disorders.
\end{abstract}

Study design: The study was observational, cross sectional \& analytical in nature.

Place and period of study: Department of Anatomy, Sir Salimullah Medical College, Dhaka, during the study period of 2005 to 2006.

Materials and Methods: Six good Mallory-Azan stained histological slides, section from proximal $2 \mathrm{~cm}$ of right renal arteries of three age groups (lower 8-29 years, middle 30-40 years, higher 42-92 years) were prepared for this study.

After standardizing the ocular micrometer with the stage micrometer for the particular objective and eyepiece, each study slide was placed in the place of stage micrometer and intimal thickness was measured in ocular micrometer division.

Result: The present study revealed that mean intimal thickness increased along with increasing age. Unpaired student ' $t$ ' test for statistical analysis revealed significant differences $(p<0.001, p<0.01)$ in mean intimal thickness of right renal artery, between the lower and middle age groups as well as the lower and higher age groups.

Key words: Intimal thickness, right renal artery, postmortem.

\section{Introduction:}

Atherosclerosis is the most common and important pattern of arterial disease, causes thickening and hardening of the arterial wall ${ }^{1}$. Despite changes in life style and the use of new pharmacologic approaches to lower plasma cholesterol concentration, atherosclerosis and its complications are still the major source of morbidity and mortality in the industrialized world and much of $\mathrm{Asia}^{2}$ and estimates have been offered that at its present rate of growth, it will be the major cause of death by the year 2020 in the entire world ${ }^{3}$.

1. Associate Professor \& Head, Department of Anatomy, HFRCMC, Dhaka

2. Professor \& Head, Department of Anatomy SSMC, Dhaka

3. Professor \& Head, Department of Anatomy, DMC, Dhaka

4. Principal, Comilla Medical College, Comilla

5. Associate Professor, Department of Physiology, Ibrahim Medical College, Dhaka

Correspondence: Saifun Naher
Atherosclerosis refers to a group of disorders that have a common thickening and loss of elasticity of the arterial walls. The changes of atherosclerosis initially involve the intimal layer of the arterial wall in which there is focal accumulation of a variety of complex lipids, proteins and carbohydrates, cellular components, such as smooth muscle cells and macrophage like cells, blood and blood constituents and in more advanced lesion, high concentrations of mineral, particularly calcium ${ }^{4}$.

Renal arterial atherosclerosis may lead to renal stenosis. The advanced lesion of atherosclerosis reduces the blood flow in arteries and ultimately leads to occlusion of the individual arteries ${ }^{5}$. Diverse renal diseases including atherosclerotic renal disease, accounts more than one third of all causes of end stage renal disease( ESRD).Atherosclerotic plaques are present in up to $30 \%$ of patients with chronic kidney disease(ARVD) is among the 
common cause of chronic disease in Western Societies ${ }^{6}$.It had been documented that atherosclerosis preferentially affects the proximal portions of renal arteries ${ }^{7}$.Other researchers defined the site as the region $1-2 \mathrm{~cm}$ downstream from renal osteum $^{8}$. Hence, the present study had been made to find out the intimal changes directed towards measuring intimal thickness of right renal artery of Bangladeshi males of different ages.

\section{Materials \& Methods:}

The proximal $2 \mathrm{~cm}$ portion of right renal artery were taken for microscopic study. The specimens for present study were collected from the subjects divided into lower (8-29), middle (30-40) and higher (42-92) age groups.

\section{Preparation of slides:}

The proximal $2 \mathrm{~cm}$ portion of right renal arteries were taken for microscopic study. The arteries were kept in Carnoy's fixative for at least 6 hours. After fixation, each segment of artery was washed in tap water and were processed for dehydration, infiltration and embedding in liquid paraffin separately. Six micron thick cross sections were prepared from the blocks. For right renal arteries sections were made from 18 (6x3) blocks from eighteen different individuals selected through random samping. The sections were mounted on slides, stained, and cover slipped. From each block three sections were taken.Section from all these blocks were stained with MalloryAzan Stain.

One good slide from six different right renal arteries of each age group were taken for microscopic measurment. Thus, a total number of eighteen (18) Mallory-Azan stained slides were used for microscopic study.

Measurement of intimal thickness:

Good, Mallory-Azan stained sections were taken for this study. The slides were examined under light microscope for measuring intimal thickness using $\mathrm{X} 10$ Objectives and X10 eye piece.

A piece of transparent plastic sheet (about cover slip sized) was divided into four equal quadrants by drawing two straight lines at right angles to each other by a fine sharp niddle( Figure.1). Then it was placed on the studying section in such a way that meeting point of the two straight lines was placed at the centre of the lumen of the artery so that the artery was divided into 4 more or less equal quadrants. Then under a light microscope, the greatest thickness of the intima were measured for each quadrant. The mean of these four values were taken as an estimate of intimal thickness of the right renal arterial sections.

For measuring the intimal thickness, an ocular micrometer was put into the eye piece of a light microscope. A metalic 'slide' standardized in length, breadth and thickness with conventional glass slide was put on the stage for standardization of the ocular micrometer. The metalic 'slide' has an in-built micrometer (the stage micrometer) at its central glass made part was used for measuring intimal thickness. The slides were examined under light microscope for measuring intimal thickness using X10 Objectives and X10 eyepiece as mentioned above. The magnifying power of the eye piece was kept constant (X10).

After standardizing the ocular micrometer with the stage micrometer for the particular objective and eye piece, each study slide was placed in place of stage micrometer and the intimal thickness was measured in terms of ocular micrometer division. The number of ocular micrometer divisions was then converted into absolute values in $(\mu \mathrm{m})$ micrometer.

\section{Result:}

The intimal thicknesses of the right renal arteries in the different age groups are presented in Table 1.

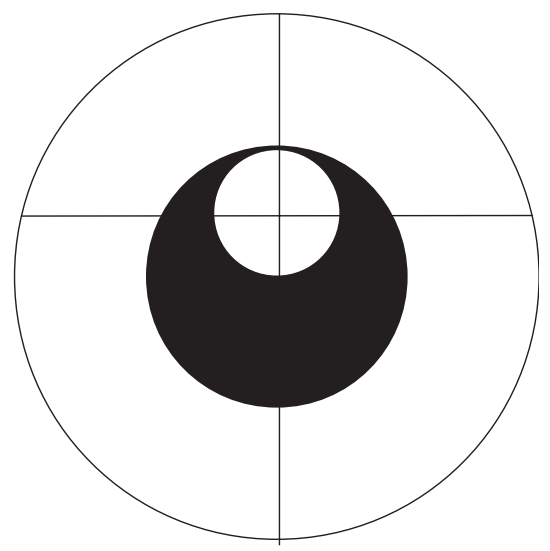

Fig.- 1: Diagrammatic representation of the division of plastic sheet into four equal quadrants and its placement on the blood vessel for measuring its intimal thickness from the apical surface of the endothelium to the internal elastic lamina. 
Bangladesh J. Anat. 2009; 7(2) : 105-108

Table-I

Comparison of mean $\pm S D$ of intimal thickness of the right renal arteries in three age groups.

\begin{tabular}{lccc}
\hline $\begin{array}{l}\text { Age group } \\
\text { (years) }\end{array}$ & $\begin{array}{c}\text { Number of right } \\
\text { renal artery }\end{array}$ & \multicolumn{2}{c}{ Intimal thickness (in micrometer) } \\
\cline { 3 - 4 } Lower (8-29) & 6 & $48.93-118.45$ & Mean \pm SD \\
Middle (30-40) & 6 & $95.28-154.50$ & $71.24 \pm 21.54$ \\
Higher (42-92) & 6 & $95.28-178.53$ & $128.75 \pm 21.54$ \\
\hline
\end{tabular}

'p' valuesLower age vs Middle age $<0.001^{* * \star L}$ Lower age vs Higher age $<0.10^{\star *}$ Middle age vs Higher age $>0.50^{\text {ns }}$

Statistical analysis done by unpaired student's 't' test, ns=not significant, ${ }^{* *}=$ significant, ${ }^{* \star *}=$ significant.

From the table it is revealed a trend of increasing the mean intimal thickness of the right renal artery in each age group along with the advancement of ages. It is also evident from the table that a significant difference $(p<0.001, p<0.01)$ was found in mean intimal thickness of right renal artery, between the lower and middle age groups as well as the lower and higher age groups. No significant differences were found between middle age group with lower and higher age groups of the right renal artery.

\section{Discussion:}

A general trend of increasing in the thickness of the intima of right renal arteries with increasing age has been showed in the results of the present study. Similar opinion had also been made in a study with coronary artery by the previous researcher ${ }^{4}$.

Mean intimal thickness of the right renal artery showed a age dependant changes in the present study. That is, thickness increased along with the advancement of ages. Thus the present study showed the general trend that the mean intimal thickness increased from the lower (8 -29 years) through the middle (30-40 years) to the higher (4292 years) age groups. This finding was quite in conformity with the finding of the previous researchers working with thoracic aorta, coronary arteries and also abdominal aorta ${ }^{4,9,1}$. The difference was statistically significant in the lower and middle age group as well as lower and higher age group. The explanation might be given on the basis of anatomical and haemodynamic factors. We know at the site of branching there is alteration in the direction of blood flow and blood flow becomes turbulent instead of laminar flow. The type of blood flow is a determinant factor in the genesis of atherosclerosis. We know, right renal artery is larger than the left renal artery. Therefore the atherogenic effect of the flowing blood through it persists for longer time than that in the left renal artery. Thus it become more prone to the development of the atherosclerosis.

Many studies had been performed to find out the pathogenesis of this disorder where the cause of increase thickness had been pointed out. It became evident from the previous research works that atherosclerosis is a disease that stimulates proleferative changes in the different cellular components of the arterial wall as well as stimulates the secretions of certain chemotactic substances that attracts the blood elements to invade the intima and to proliferate. All these biochemical changes ultimately lead to the increase in the intimal thickness ${ }^{10,2}$. As it is a progressive disorder this process of thickening is most likely to continue at an increasing rate as age advanced.

\section{References:}

1. Schoen FJ Cotran RS. Blood vessels. In: Cotran RS, Kumar V, Collins T, editors. Robin's Pathologic Basis of Disease. $7^{\text {th }}$ ed. Philadelphia: WB Swanders Company, 2004; p. 516-25.

2. Ross R. Atherosclerosis-An inflammatory disease. N Eng J Med 1999;340:115-26.

3. Joseph L. Thematic reviews on the pathogenesis of atherosclerosis. J Lip Res 2004; 45(6): 991-2. 
4. Begum S. Postmortem study of atherosclerosis in the abdominal aorta of Bangladeshi males [thesis]. Dhaka: BSMMU; 1998.

5. Kaatee R, Beek FJ, Verschuyl EJ, Ven PJ, Beutler JJ, Schaik JP et al. Atherosclerotic renal artery stenosis. Radiology 1996; 199 (3): 40-63.

6. Pohl MA., Novick AC. Natural history of atherosclerotic and fibrous renal artery disease: clinical implications. Am J Kidney Dis. 1985; 5(4):120-30.

7. Libby P. Diseases of Blood Vessels. In: Isselbacher KJ, Braunwald E, Wilson JD, Martin JB, Fauci AS, Kasper DL, editors,
Harrison's principle of internal medicine. 15ed. New York: McGraw-Hill Inc, 2001; p. 1377- 88.

8. Yamamoto et al. Blood velocity profiles in he human renal artery by doppler ultrasound and their relationship to atherosclerosis. Atherosclerosis 1996;16:172-77.

9. Islam MS. Postmortem study of atherosclerosis in the aorta and coronary arteries in Bangladeshi males [thesis]. Dhaka:University of Dhaka;1996.

10. Boon NA, Fox KAA. Cardiovascular disease. In: Edwards CRW, Bouchier IAD, Haslett C, editors. Davidsons principle and practice of medicine. $19^{\text {th }}$ ed. London : ELBS with Churchill Livingstone, 2002; p. 420-23. 